\title{
Calculation of the foundation settlement during compensation grouting
}

\author{
Ivan Luzin* and Lyubov Ermoshina \\ Moscow State University of Civil Engineering, Yaroslavskoe shosse, 26, Moscow, 129337, Russia
}

\begin{abstract}
The article presents the issue of correctly calculating the SSC of the foundation bases in the process of compensation grouting. It is shown that the numerical calculation should be performed in two versions: hydrostatic pressure and rear volume strain in a cluster of soil. Using the example of an object in Moscow, the use of the PLAXIS 3D design complex was shown to calculate additional precipitation of buildings during compensation grouting and the passage of a tunnel under it. A method is given for determining the required volume of suspension during compensation grouting using numerical methods for calculating the SSC.
\end{abstract}

\section{Introduction}

The development of modern cities creates the need to improve the transport accessibility of new areas. One of the ways to improve is the construction of new stations and metro lines. However, in the construction of new tunnels in their area often there is additional displacement of buildings. They are due to technological features: with the passage of the diameter of the excavation slightly exceed the final diameter of the tunnel, which causes movement of soil in the area of excavation. Such a process is sometimes called "ground overrun" and is taken into account. In some cases, foundation settlement can be more than the limit value given in SP 22.13330.2016. In such conditions, there is a need for additional measures to reduce additional environmental precipitation. One of these methods is compensation grouting.

Compensation grouting is one of the most effective methods of protecting buildings and structures during the construction of underground structures in their active zone. This method consists of injecting a slowly hardening mineral-based solution into the soil base of a building or structure to compensate for or control its additional settlement. [1-2] Compensation grouting at the base of buildings and structures is carried out in several stages:

- creation of a homogeneous "matrix" of the fortified soil by injecting a special compound into it;

- pre-suspension of the suspension to create a uniform stress state under the entire structure, which allows you to further point-compensate the structure precipitation as needed;

\footnotetext{
* Corresponding author: inluzin@gmail.com
} 
- the main stage of the suspension injection with the beginning of the construction of an underground structure;

- forcing the suspension after construction to stabilize the settlement at the base of the building or structure.

\section{Methods}

In the process of tunneling and at the same time compensatory injection in the ground, a complex stress-strain state is formed. To calculate the SSC in this case, it is advisable to use numerical methods, in particular PC PLAXIS, which implements the finite element method.

When calculating the compensation grouting in the PLAXIS software, the question arises of the correct setting of the injection parameters for calculating the SSC. The two main methods of setting the compensation injection are:

- setting the hydrostatic pressure corresponding to the suspension pressure within the selected cluster;

- setting a volume strain to a dedicated cluster.

The choice of the compensation injection method in the model should proceed from the required output calculation parameters. So, for example, if it is necessary to calculate additional deformations when sinking a tunnel under a building, it is necessary to set the compensation grouting with hydrostatic pressure, and when determining the required volume of suspension, the volume strain of the cluster. 


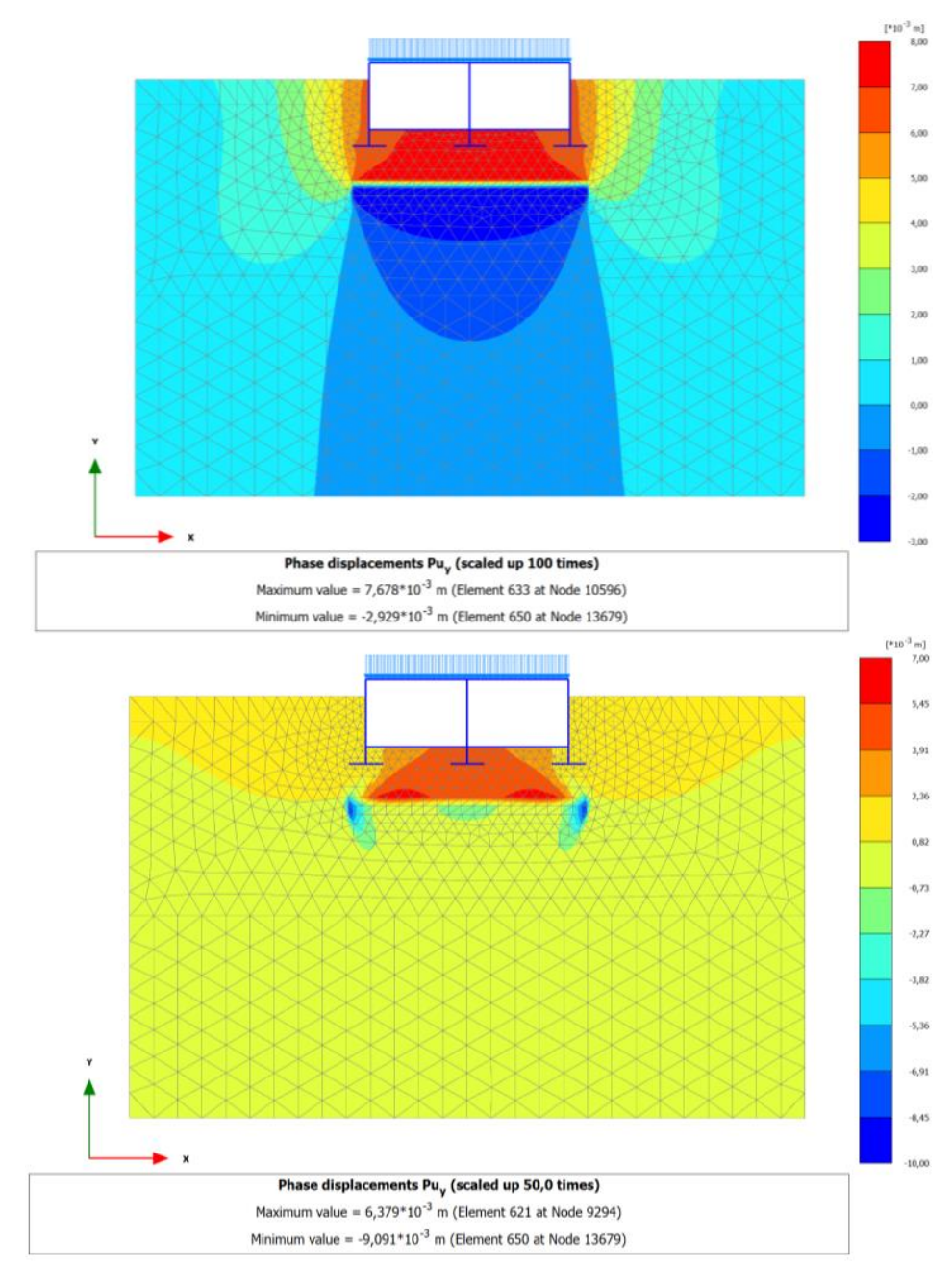

(a)

(b)

Fig. 1. An example of using PLAXIS 2D for calculating additional displacements of foundations during compensatory injection with a rear volume of cluster deformations (a) and hydrostatic pressure inside the cluster (b)

\section{Results}

We give an example of calculating the required volume of suspension when tunneling in Moscow under the existing building.

When tunneling diameters of 10.3 meters under the industrial workshop, it became necessary to reduce the estimated additional displacements. The workshop is a building with a full reinforced concrete frame. The category of the technical condition of the building as a whole is characterized according to GOST 31937-2011 as "efficient", and according to Attachment D SP 22.13330.2016 "Grounds of buildings and structures" - II "satisfactory". Consequently, the marginal additional displacement of this building is 3.0 $\mathrm{cm}$, and the relative difference of sediment is 0.001 . In the course of preliminary calculations, it was found that the calculated additional displacement of the building exceeds the standard, and therefore it was decided to conduct a compensation grouting at 
the base of the building foundations. In this case, the search of the soil was set equal to $1.8 \%$ along the entire length of the tunnel. Due to the fact that the described building is located in dense urban development, there is no possibility of constructing a technical pit for carrying out horizontal drilling for injectors, therefore, the circuit shown in Figure 2 was chosen for carrying out the compensation injection. However, such a scheme somewhat reduces the efficiency of the compensation injection, and therefore requires a greater flow of the suspension. [3-6]

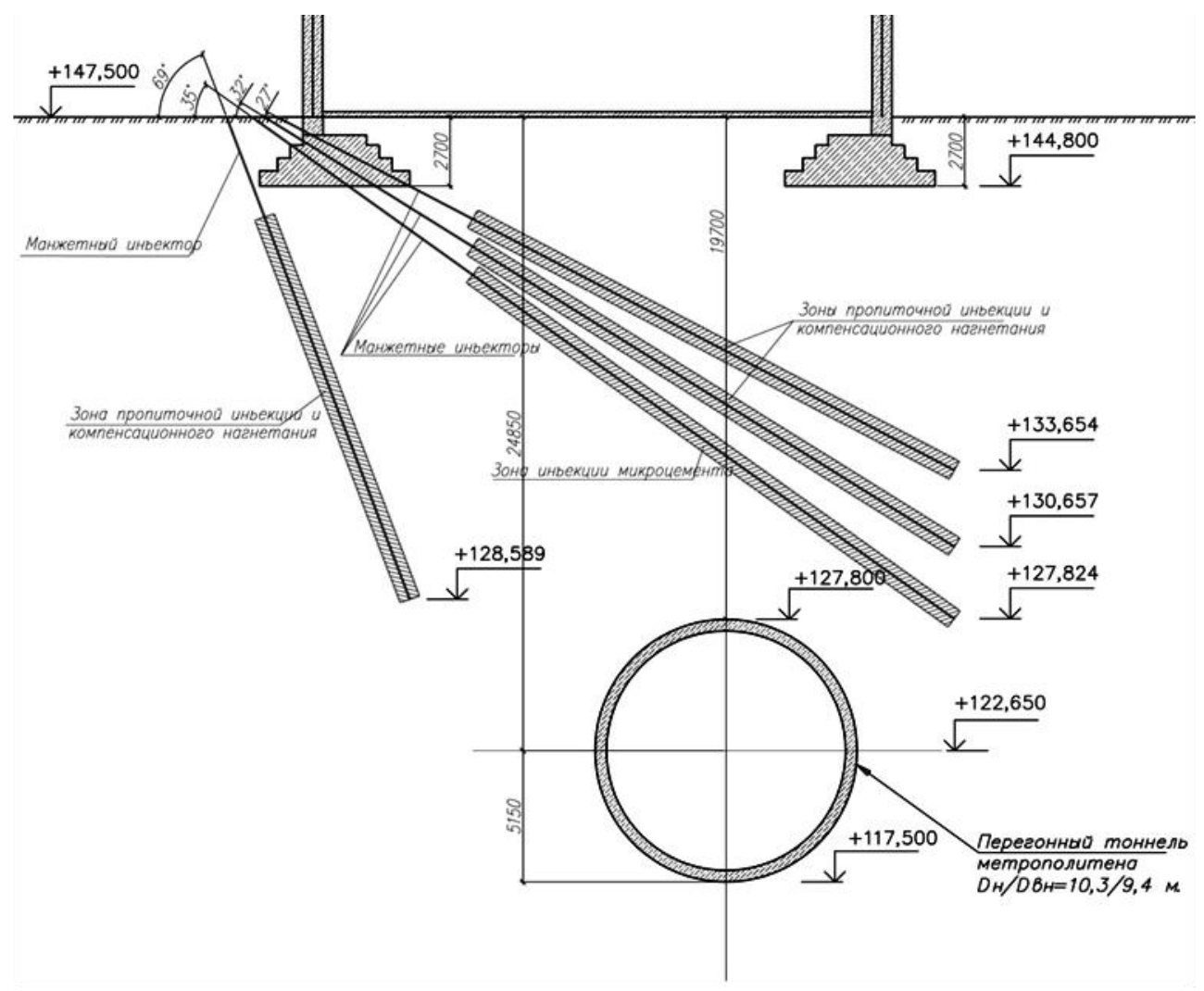

Fig. 2. Scheme of the work of the compensation grouting

When calculating the SSC of the system, it is also necessary to take into account the relative position of the building and the tunnel in the plan, as well as the change in the depth of the tunnel relative to the foundations of the building. In the event that the mutual arrangement of the tunnel and the building both in the plan and in the section can be taken parallel, then a two-dimensional calculation of the section can be considered sufficient for a correct calculation of the system SSC. However, in this case it is necessary to make calculations on several sections in order to assess the effect of a change in geological conditions on the estimated displacement of a building. In the case when the relative position of the building and the tunnel differs from the parallel, the spatial formulation of the problem should be used. [7]

In this case, the spatial formulation of the problem was adopted, since the tunnel has a complex shape, both in plan and in section. Figure 3 shows the plan and section of the tunnel. 


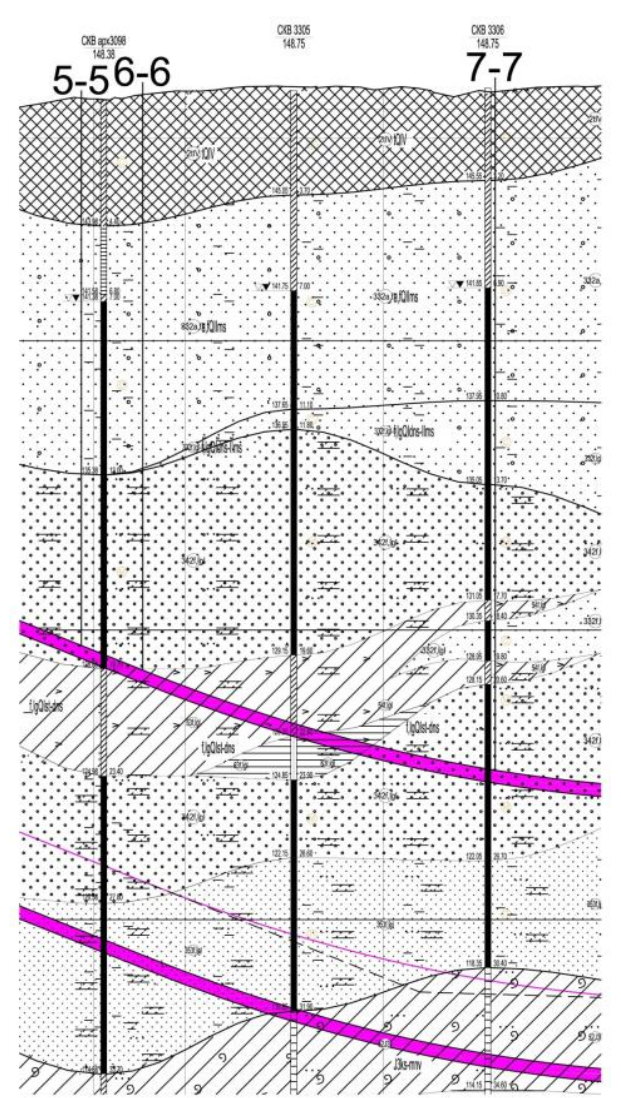

(a)

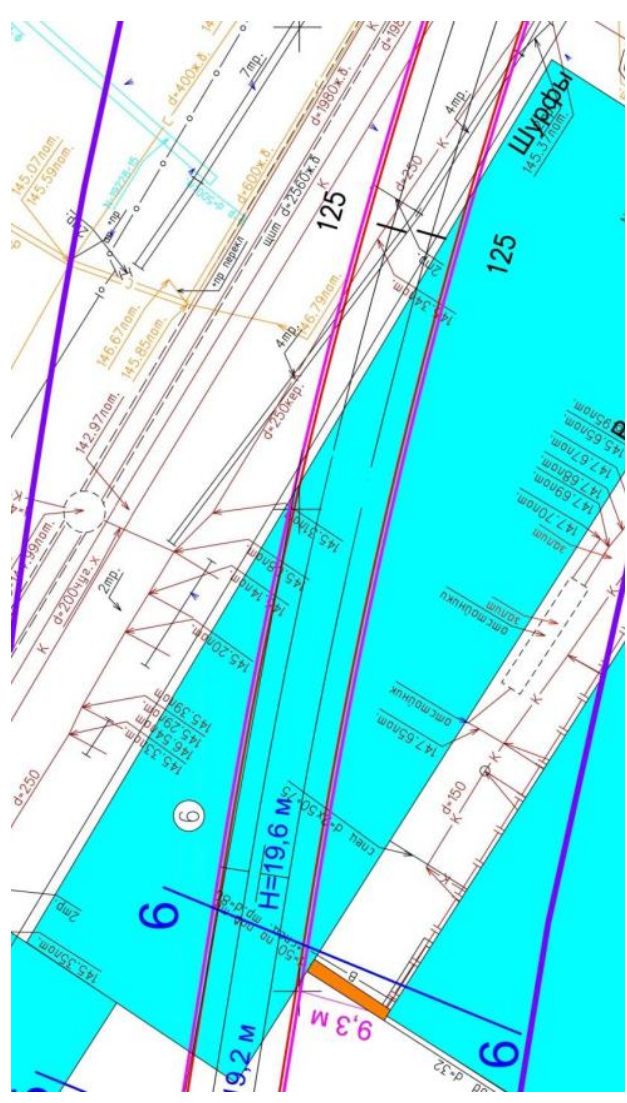

(b)

Fig. 3. The location of the tunnel on the engineering-geological profile (a) and in terms of the building in question (b)

The main task of the calculation was to determine the required volume of suspension to compensate for the settlement during the tunneling under the building, therefore, the method of calculation with volumetric cluster expansion was chosen. When building a finite element model, the heterogeneity of the site's geotechnical conditions, the spatial rigidity of the building and the phasing of the tunnel under the building were taken into account. [8-9] 


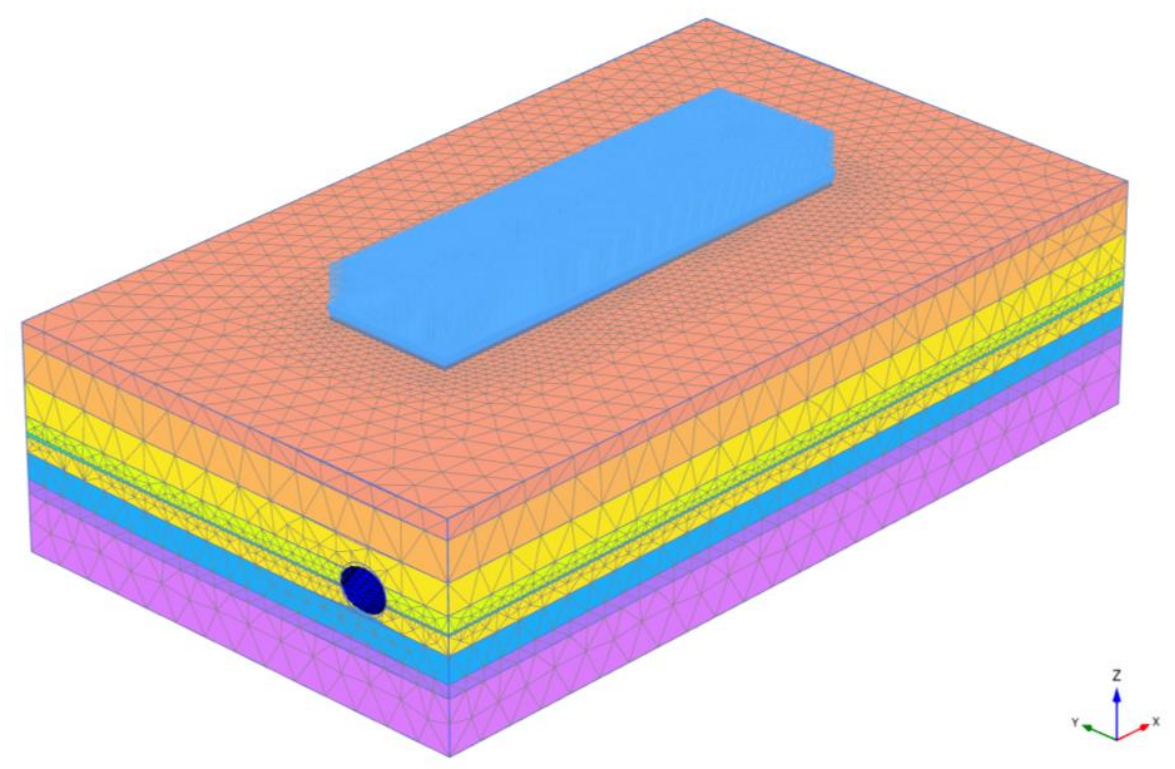

(a)

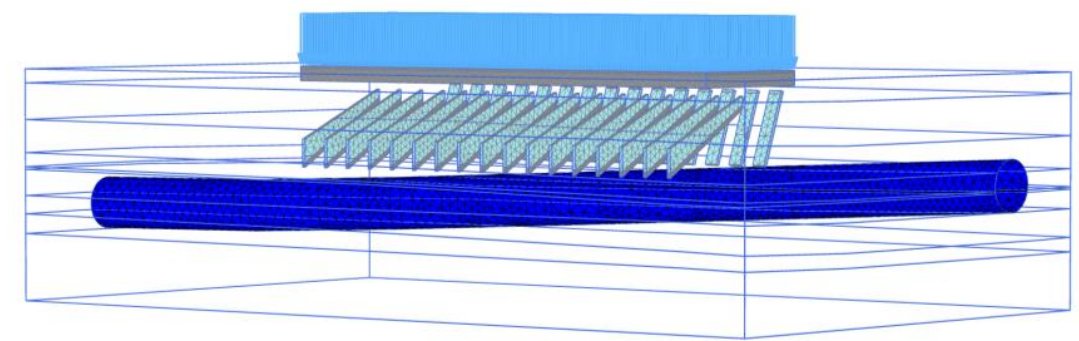

(b)

Fig 4. The design scheme of the tunnel and the surrounding buildings, taking into account the geotechnical conditions (a) and taking into account the compensation grouting scheme (b) (clusters of soil are turned off for clarity)

To take into account the phasing and more correctly calculate the volume of the suspension during compensation grouting, the tunnel was divided into 11 parts. The calculation was carried out in several stages, with the sequential switching on of the next grab of the tunnel and compensation grouting to level the deposit of the building above it. The required volume of the injected suspension and, as a result, the necessary proportion of volume strain was determined by the method of successive iterations. [10]

Thus, as a result of the calculation, additional deformations of the building foundations were obtained when the tunnel was sinking, taking into account compensation grouting. These deformations do not exceed the maximum permissible, therefore, the compensation grouting method can be considered effective from the point of view of preventing unacceptable deformations. It is also worth noting that the above method of calculating the additional settlement of the foundations, taking into account the tunnel penetration and compensation grouting, allowed us to construct a map of the required volume of suspension on each injector. 


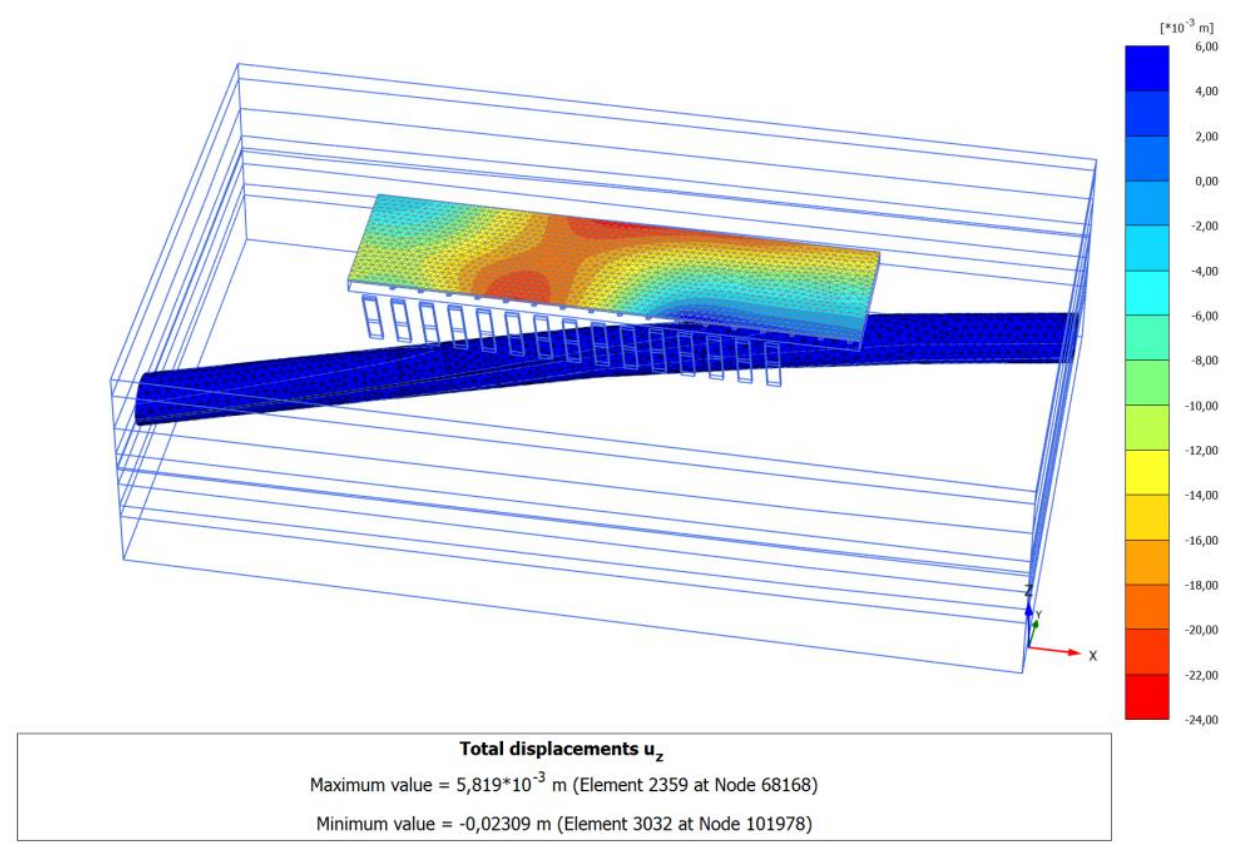

Fig. 5. Additional displacements color shadings in the end of tunneling and compensation groutng

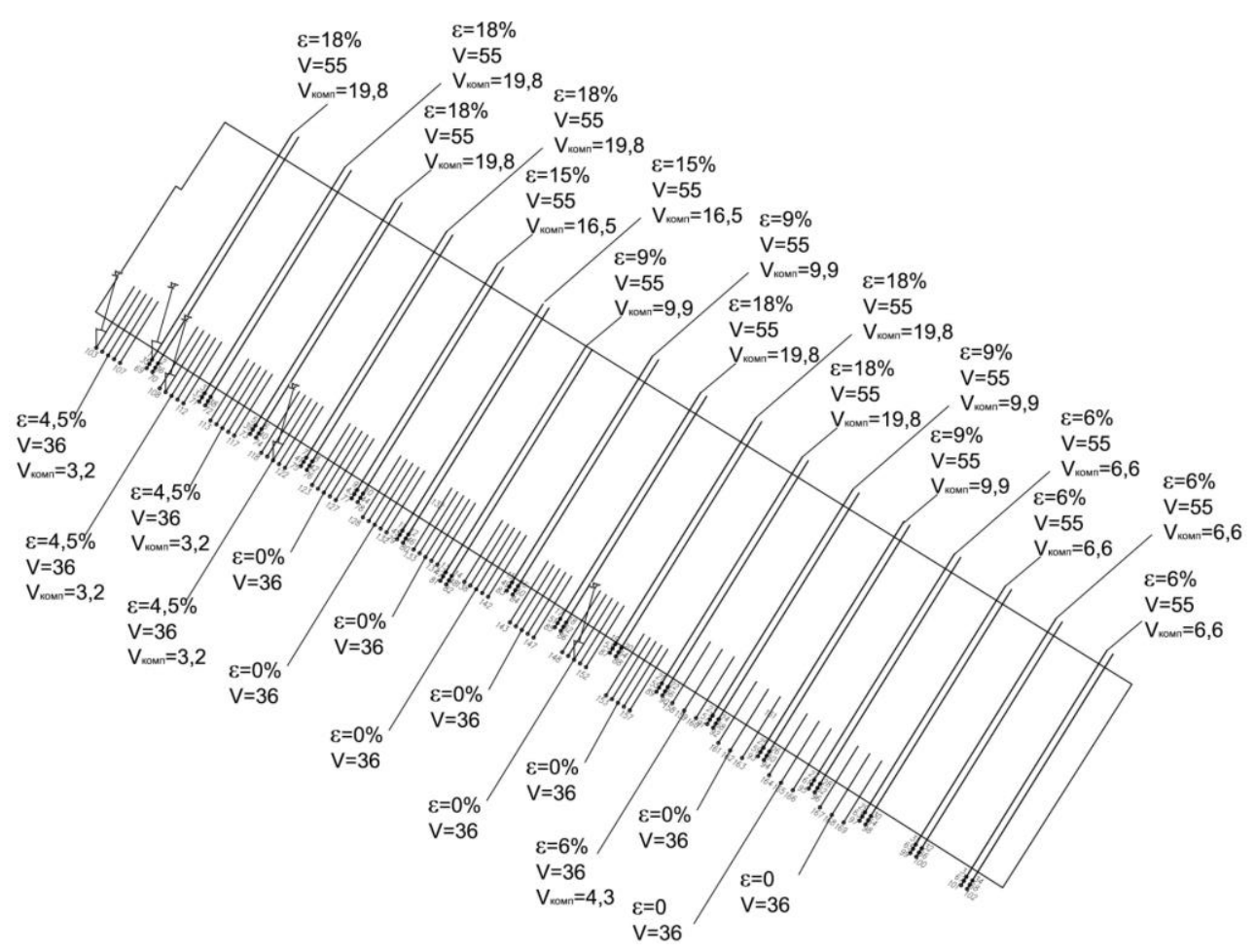

Fig. 6. The map of the required volume of suspension on each injector 


\section{Conclusion}

1. During the construction of underground structures and tunnels in dense urban development, preliminary calculations should be made of the settlement of the surrounding buildings. When the estimated displacement is exceeded the maximum permissible values, additional measures should be taken to protect buildings and structures.

2. The method of compensation grouting is an effective method to prevent intolerable sediments of the surrounding buildings. However, numerical calculations require the correct setting of all parameters of the compensation grouting for satisfactory calculation accuracy.

\section{References}

1. C.P. Zhang, X. Zhang, Q. Fang, Tun. and Undergr. Sp. Tech. 81, 121 (2018)

2. X. Li, D. Yuan, Tun. and Undergr. Sp. Tech. 72, 73 (2018)

3. W.J. Rankin, Eng. Geol. of Undergr. Mov. 5, 79 (1988)

4. S. Jancsecz, W. Steiner, Tunneling'94, 531 (1994)

5. Y. Zhang, W. Li, D. Li, J. of Wuh. Un. Of Tech. Mat. Sci. Ed. 32, 1115 (2017)

6. J. Fillibeck, M. Sailer, M. Kretschmer, Bauing. 92, 323 (2017)

7. R. Schneider, A. Garcia-Fontanet, A. Ledesma, R. Raveendra, T.P. Orodea, Can. J. of Civ. Eng 46, 87 (2019)

8. J. Li, H. Liu, G. Kong, Rock and Soil Mech. 38, 479 (2017)

9. G. Zheng, X. Zhang, Y. Diao, Nat. Haz. 83, 1683 (2016)

10. B. Ring, M. Comulada, Undergr. Sp. 3, 297 (2018) 